\title{
The Semiotic Immersion of Video Games, Gaming Technology and Interactive Strategies
}

\author{
Eduardo Neiva \\ Professor of Communication Studies \\ University of Alabama-Birmingham \\ ecneiva@yahoo.com \\ and \\ Carlo Romano \\ Virginia College and American Sentinel \\ Birmingham, Alabama \\ and \\ CEO of 3Romans LLC \\ carlo@3romans.com
}

\begin{abstract}
The paper analyzes the effect of immersion in digital games using the theoretical apparatus of game theory. The paper illustrates interactive operations and the cause and effect relationship between player and designer, explaining the importance of strategic decision-making and pathing in player immersion. It considers the game function of creating a virtual world and proposes the idea that digital games are not just computer-mediated communication to the player. These games are games of "the moment", like the game Chicken, and played with apparently great emotion, intelligence, and physical dexterity, although represented in software form. The relationship between the player and the computer is one of sign exchange, precisely the one that semiotics calls semiosis. The paper concludes that the personal achievement of individual players (end-users) accounts for the phenomenon of deep immersion in digital games. Not virtuality, but virtuosity is the strong force in digital game playing.
\end{abstract}

More than the word game is present in both video games and game theory. At first glance, it is improbable that concepts designed to explain economic transactions (Morgenstern and von Neumann 1944, and Nash 1950 [1997]) or even evolutionary biological enigmas (Maynard Smith 1982) and other modes of conscious interaction between human players could be of any use to elucidate what succeeds when a rational individual faces deep interaction with a mechanical computer ${ }^{1}$ or a software application.

Because of the popular interest in video games, considered to be the forefront of the new media, academics, social theorists, and even industry participants have systematically tried to define and understand games as they relate to traditional genres of entertainment and social tendencies. Such attempts fail to address in depth the key factor of games - strategy, and do not take into account the amount of interaction and the degree of immersion typical of video games. Interaction and immersion through semiotic input and output is not only what differentiates games from other media like film, TV, and books, ${ }^{2}$ but also what explains the novelty of the games and the effect they exert over players. In this paper, game theory is presented as the alternative to the prevalent theoretical tendency to search (albeit

\footnotetext{
${ }^{1}$ Mechanical Computer is a reference to the hard drive or component configuration of a computer.

${ }^{2}$ An example of this standpoint is Rollings and Morris' (2004:11) statement: "an interactive game is no different than a work of 'classical art'. For example, if you read the epic poem, The Iliad, you construct your own unique narrative, which certainly differs from what Homer had in mind."
} 
from the outside and with a dangling grasp of the interactive structure of gaming) for analogies linking well-established conceptual systems from sociology, media effects theory, philosophy, studies on literary narrative, or psychology, to game playing.

We will argue that the interactive exchange of game design, delivery, and immersion made possible through signs circulating between humans (end-users) and computers brings exponential consequences on the player and the contemporary state of game design. As the gaming experience unfolds, the act of playing (gameplay) defines the user's ability as he/she acts in a virtual world with its own laws, rules, modes of gameplay, and degrees of freedom. Moreover, we maintain that the theoretical apparatus to clarify the gaming experience is found in game theory, because game theory is fully committed to explaining the processes of interactive decision-making.

Our approach to this subject arrives from both an academic and professional perspective. ${ }^{3}$ Communication principles and game theory when applied to game design and player response illustrate not only the function of strategic gameplay, but also how interactive decision-making is the vital component of immersion. To examine this process better, first, there must be a mutual understanding between the perspectives.

Concepts and discussions of video games, in the academic and professional world, should come to an agreement of terms before progress can be made in defining the attributes of playing games. Although, a tug-of-war is probable, both having ownership over games, neither should forget that it is the players that define the terms mostly and evolve these terms to have specific meanings. Terms used in this paper will apply the common usage and meaning, as it is related to the subject. An example of this is the term cue, which is a category of sign, but in regard to game design specifically it is a device used to direct the player's progress, or virtual worlds which is commonly known as the construct in which the player's representation in the game exist, usually replicating reality with $3 \mathrm{D}$ or $2 \mathrm{D}$ art.

Game testing and player feedback solidifies concepts that work in games and is used here to discuss game design and player immersion. Many specific comments come from the professional experience of overseeing a process called, Quality Assurance $(Q A){ }^{4}$ This process includes addressing development issues with the Producer responsible for the end product being a success in the market, fixing all software defects, and most important making the army of testers agree that the game is finally fun and worth playing.

\footnotetext{
${ }^{3}$ The authors represent both academia and professional game design. Eduardo Neiva Ph.D. is a Professor of Communication Studies, University of Alabama-Birmingham and an authority on visual images. Carlo Romano, CEO of 3Romans LLC is a professional game designer, and a teacher of Game Design at Virginia College and American Sentinel in Birmingham, Alabama.

${ }^{4}$ Quality Assurance and game testing is a process that resembles a focus group, organized to determine if the game is immersive, intuitive, bug-free, and most of all - fun. The Project Manager and/or Game Designer manage this process. Carlo Romano, a 10-year veteran game designer, has overseen this process many times with groups of testers and producers to coordinate with. The information gleamed from this experience is illustrated in specific comments in the text. A list of the titles observed, during the testing stage of Alpha, Beta, and Gold Master, is provided: Country Justice, (2005); RebelTrucker, (2004); Ultimate Demolition Derby, (2003); Muscle Car 3, (2003); Muscle Car 2, (2002); Roadrage, (2001); Boards and Blades 2, (2000); Tech Bike BMX, (2000); Shwinn's Freestyle BMX, (2000); Bass Tournament 3D, (1999); E xtreme Boards and Blades; (1999) - All titles required at least twenty testers at each stage.
} 
It is important to understand what is common in all games before discussing the impact of a specific type of game on a player. Additionally, it is the player and his interest that should be in the forefront of talks about games. This provides a foundation for future discussions about evolving genres and innovative features that are the driving force behind the popularity and level of immersion only attainable in games. Research on the sociological effects of games or theories about the relationship between games and other mediums are beneficial, but only conclusive in respect of the limited gameplay scenario.

Research attempting to enter the world of video games has found it quite difficult to separate the game's design from the designer's own biases, and therefore has problems simulating the interaction needed to explore social tendencies. Holin \& Sun (2003) - for example - found the designers of the research application (game) preferred what is commonly considered fun factors to gender and social representation. This fact changed the goals of their research and illustrates why there must, first, be collaboration between academia and professionals concerned with studying video games and game players. This paper unifies these two perspectives, and although giving credit to other research goals, identifies the fundamental elements of game playing, game design, and how both are affected before addressing the effect of the game or the game design on the player.

Taking into account the fact that many players engage in role-playing with a community of immaterial individuals living a virtual life quite the opposite of their daily routine, Sherry Turkle (1996) argues that game playing is an "identity workshop", suggesting that the use of computers is a healing tool to repair uncomfortable, fractured, or damaged selves. After defining the computer as "an evocative object because it provoked self-reflection and stimulated thought", Turkle (1996: 362) levels human players and cyber-machines, claiming to have acquired, as a result, a new perspective on the nature of intelligence, free will, and life in general.

Although it is correct that a new perspective on intelligence and human will is revealed through the use of video games, as the player manages his/her own strategic choices in risk-taking, Turkle's approach tends to merely humanize the computer. The title of Turkle's earlier book - The Second Self (1984) - suggests that the computer is subaltern equipment in the hands of the user.

It may well be that cybernetic role-playing in games is an effective therapeutic tool of lasting value. It may also be a counseling tactic that unveils a horizon of experiences for introverts and individuals locked up in rigid presumptions crippling, maiming, or impoverishing their lives. If, for example, gender swapping is readily available for end-users, they will then acquire a new human perspective and an array of experiences usually barred from their regular interactions. Playing games generates personal and social effects. However, objections can be raised to support the criticism that a research such as this does not quite deal with the nature of games. In Turkle, what really matters is role-playing. Game playing and its peculiarities are visibly absent in this approach.

Another analytical tactic dealing with the problem of games could be to consider games from their components. If the player is frequently following semiotic and narrative cues, being involved as well as attempting to unravel a tale, it is tempting to presume that literary theories concerned with the issues of narrative could be the key to the experience of game playing. Here the objection is not any different from the one observed in the case of therapies of role-playing: Is a digital game a secondary literary object or a product with its own peculiar qualities? Bogost 
(2006) argues that similar principles are at work in literary analysis and computation, which would in turn be extensive to games.

To avoid the mutation of game questions into what should pertain to literary analysis of narratives one ought to find crossroads where the study of games intersects with the study of narratives. Bogost (2006: 67) observes: "we use narratives to make sense of experiences, and games have embedded stories and backstories that are undeniably narrative". In this remark, the commonalities of games and narratives are obviously articulated, but that does not in itself lead to the fullest understanding of games. Consider the case of the skateboarding game Extreme Boards and Blades, in which the player is offered a style of gameplay called Freestyle. In the Freestyle mode of playing, the player is free to skate in an open area with no restrictions, goals, or obligations. The player experience is measured only in relation to his/her performance and not to any narrative elements or storyline. Moreover, the lack of narrative is more common in games that aim at pushing the boundaries of design, thus offering to players the opportunity of living the extremely personal experience of transforming his/her previous capacity and performance.

The solution to the quandary of giving analytical priority or not to narrative may reside not in the search for common points between narration and gameplay, but in their distinction. In games, the player is at the core of the gaming process, while, when compared to the deep intensity of game immersion, the power of literary narratives comes from a relative sense of alienation, for the reader of literary narratives always acquires knowledge from the distance, from a radically external viewpoint, whether in the obvious case of a story told from the perspective of a third person, or else reading a tale told by a character directly involved in the scene, in other words, by a first person narrator, who is obviously not the reader.

When compared to traditional literary narratives, games are not experienced from afar. The players of games are immersed in a world of cues signaling the path of their navigation. If, on one hand, in some games, tales and navigation are inseparable; on another hand, the readers of traditional literary tales are consistently aware that they are not the narrators (in the third or first person narrative) who supposedly had direct experience of the fictional plot and the incidents of the story. While the reader of literature may be told of a possible world, the player of video games is acting in a world of possibilities unfolding with a force akin to direct experiences. The players are exposed to digital simulations that may, in some game designs, correspond to real events, thus allowing the assessment of risks without paying the price of living out such scenarios in reality. Games that may not require the player to accomplish any narrative challenge, like Extreme Boards and Blades $(B \& B)$, have a definite objective: They foster self-improvement. The player has a sense of self-accomplishment, when he/she skates, and is free to take risk like skating off buildings and up higher ramps, attempting more intense stunts (tricks) to achieve a higher gameplay status. The substitution of actual experiences is far more enticing and dramatic than any narrative development.

Not only does the excessive and improper use of narrative procedures often indicate poor and unimaginative game design that does not take complete advantage of gameplay possibilities, but also narratives do not define a game, otherwise many extreme sports, flight and military simulations, as well as games with open-ended gameplay could not be considered video games, and indeed they are. One defining attribute for video games stands true in every scenario - video games are devices where a player attempts to achieve something desirable through strategic actions. 
However, the player's initial expectations of wining are not relevant when measuring the impact of immersion and interaction in video games because the player always gains: When the player uses a vehicle to achieve something desirable, for example, experience is added to the existing player. The player has changed. In a general way, the player acquires information about him/herself, either negative, in the case of failure, or positive, in the case of success.

Video games take countless forms, a direct reflection of the irrepressible growth of the game industry, reaching all kinds of social actors, according to their interests and demands, regardless of race, age, gender, and social class. Statistical data about the market of games, released by the Entertainment Software Association (ESA) in its "2006 Essential Factors about the Computer and Video Game Industry", reveal that, contrary to the previous stereotype, video games are not just an exclusive medium for socially challenged teens any more. Presently the average age of game players is 33-years old, and the average age of the most frequent game purchaser is 40 -years old ${ }^{5}$. According to the NPD Group-Point-of-Sale Information, 228 million game units were sold in 2005. These figures undeniably demonstrate that games are more than just a passing trend in contemporary popular culture. The permanent economic success of video games is evidence of the demand for more and more technologically sophisticated forms of interactive entertainment. To understand the intricacies of interaction is a challenge that cannot be dismissed by the theory of the new media.

Although games are approached and enjoyed from differing perspectives, the popularity and the communication strength of games are, in all forms, related to the fact that they offer the chance for a player to live out intense scenarios in a virtual world, even if these designs are flagrantly fantastic. Games provide an emerging interaction, whose progress is previously captured in algorithmic development, performing implicit or explicit strategies that mutually circulate from player(s) to computer. Even in games such as Rebel Trucker and Grand Theft Auto 3 that provide open-ended gameplay and storylines, the player and game interaction is coordinated by active and reactive strategies. These games offer the player missions to accomplish without time limits, and therefore freedom to not participate in the common design. However, the game is also designed to incorporate and even promote deviant and rebellious acts, and has programmed a virtual world to interact with the player accordingly. What is usually called "eye candy," like pedestrians on the sidewalk, can become active, and even hostile to the player that chooses to stop the vehicle beside them, get out, and assault them. Also, police cars and beat cops can even respond to the player's anti-social behavior. The game designer may not have forecasted that the average player would act this way; but to produce a game of intense immersion, the designer must program the artificial intelligence (AI) to react and learn from such behavior. Narratives are secondary devices in playing a digital game: "There is plot in any game, but for the most part it is created by the player himself. It is the player, not the game's designer, who is the author

\footnotetext{
${ }^{5}$ The gender shift in the market of video games is also striking. Women gamers over 18 are more numerous than boy gamers under 17, according to the Entertainment Software Association. The demographics of age and gender groups transformed not only the pool of consumers but have also placed female creators and developers of casual games at the head of game developing companies (see Jan (2006) for a journalistic report of the trend). Casual games are frequently based on existing games such as bowling, tennis, and mahjong. Characteristically, casual games are made with simpler graphics, and have short learning curves.
} 
of the game's events. The game is a tool for allowing the player to create stories." (Rollings \& Morris 2003: 13).

Determined through gameplay, the player's experience does not happen in a vacuum. As shown in Fig. 1 (below), the original game design provides a game state in which the player interacts by deciding a mode of play or simply progressing through a training scenario. In each case, the player enters the virtual world through one filter, as in a color/shade wheel, and is faced with options and choices, indicated as new filters or shades of the wheel. Once the player has accessed an option, the previous filter, indeed an acquired experience is added to the new filter that loops back and changes the state of the game. Each filter of the wheel adds to the shade of the next, expressed in the wheel as lightening or darkening each time around, thus forever changing the state of the game in correlation to the player's experience. The game environment or its Virtual World grows as the players make strategic choices. Technologically, this ever-revolving and looping process accounts for greater immersion in the case of player experience, and it also prompts changes in behavior of non-player characters (NPC), and additional artificial intelligence (AI) routines and new instructions that alter the game state.

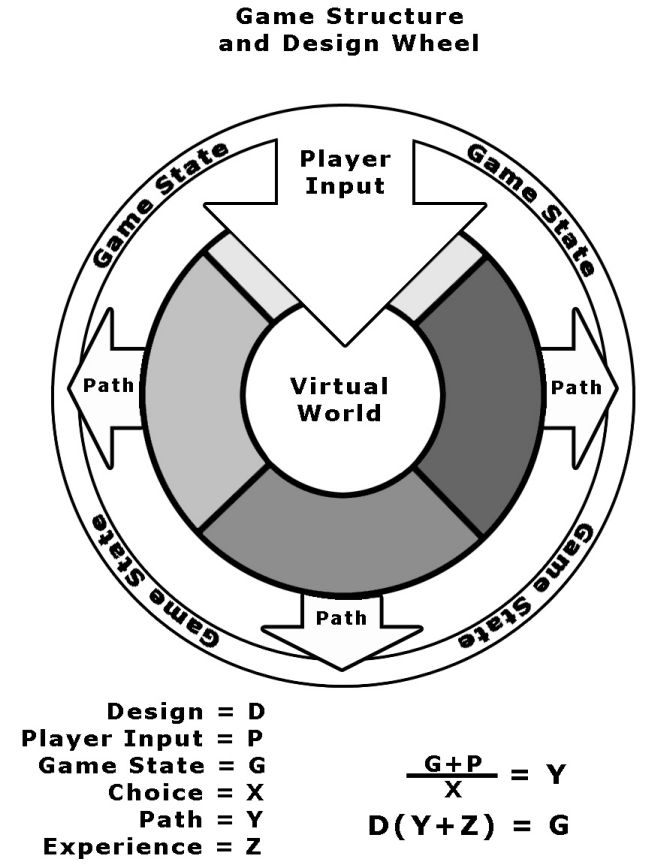

Fig. 1

The simple equation in Fig. 1 illustrates how the initial game state $(\mathrm{G})$ and player input $(\mathrm{P})$ is divided by the choice $(\mathrm{X})$, either available or taken. This choice dictates a new path $(\mathrm{Y})$ of gameplay. The original design (D) should take into account the paths resulting from the player's choice and experience $(\mathrm{Z})$, and guide the player with intuitive gameplay while providing the freedom to alter paths. The changed path is a new experience, and the new game state loops back in reaction to the player's input. This should be understood as a semiotic loop of signs, signals, cues and reactions. The reactions are both organic and scripted, both human and mechanic - generating exponential growth of the game state and the player's experience. 
If narrative is not the determining factor of gameplay, the question remains: what is the essential attribute of video games? Primarily, a game must have a point, which defines the purpose and the procedures of the gameplay. Before coming to the discussion of the point in video games, a recurrent mistake should be clarified. Points and genres should not be identified with one another. The focus on narrative dismisses the centrality of the player's role in the creation of the game's events. Genres, such as fantasy, or what Rollings and Morris (2004: 12) dubbed as J. R. R. Tolkien's rip-offs, are at best the goals of the designer, merely pushing the player into a potential direction. Narrative references to game genres may be appropriate in some cases, but lacks the needed player perception.

With this in mind, it is easy to see that Action games include sports games and games whose point requires a great deal of hand eye coordination, but so do $\mathrm{Ad}$ venture games that are usually story driven. Strategy games demand simulated interaction, and Simulations offer the player interaction that is designed to evolve skills, but so do Educational games. Then, there are Puzzle games that are considered analytical, but even so-called Toys, which are designed for the sake of fun, include puzzles. This is why most players consider genre relevant in terms of the style in which the game is played. A sample list and brief description of game genres should include, without being limited to:

- Real Time Strategy (RTS): simplified simulation of a conflict.

- Turn-based Strategy - Players move in turns (simultaneous / sequence)

- Simulation - Skill enhancer: Flight, Military, Poker, etc

- Role Playing Game (RPG) - Mostly played from character perspective.

- Action/Adventure - Storyline - played in first or third person perspective.

- Sports - Simulated or fantastic: football, baseball, golf, racing, tennis, etc

- Puzzle - Casual gaming with out character or storyline involvement.

- Educational - Directly related to the goal of learning specific content.

So, the genre is not the point of games and it is evident that, although end-users have favorite types of games, players play many styles of games, which may be irrelevant to the point of playing. Hence, the player switch favorite games, genres, and style many times depending on the performance and challenges achieved. The point of video games is not achieved through the theme or style of gameplay, but in fact the point of games is realized only though the action of end-users, and never solely through in-game scenarios.

\section{Game On}

Although theorists of games have been tempted to draw definitions of their object from Huizinga's Homo Ludens (1950 [1994]), a classic book on gaming and civilization that projects the qualities of make-believe and lack of seriousness to playing, the relationship between games (all kinds of games) and reality is not so easily established. Games and reality are undeniably distinct, and yet to play a digital game is to experience a fascinating and potential world that can be seen as a transformed surrogate of reality.

Before any attempt to comprehend how a possible world is actualized through the input and the output of digital signals, it is necessary to ponder on games and other types of game playing. Under its many forms, gaming is an experience that cannot be easily dissociated from social practices. Perhaps through make-believe and fun, and although societal interactions are not solely play, game playing is an integral 
aspect of social life. More than a couple of decades ago, Sebeok (1981) noticed that naming in animals -the application of tags to individual organisms is possible through playing. All across nature, and in many species, socialization, playing, and naming are not only directly linked, but most specifically occur through signals traveling through the sensorial channels available to the living organisms.

The social trait of gaming is evident in the fact that playing a game is a recurrently interactive practice. For that reason, since von Neumann and Morgenstern's book of 1944, The Theory of Games and Economic Behavior, economic game theory postulates generally that games are not just recreational activities, but also any situation in which the interest of players collide. As a theory of conflict of interest, game theory deals with haggling and bargaining, buying and selling real state or stocks, labor negotiations, warfare, and political disputes among other human interactions. In situations such as these, a player develops plans of action with the goal of obtaining gains and advantages, but considering primordially what the opponent may do. For that reason, game theory should not be concerned with the evaluations of optimal strategies in abstract; it indicates what strategy or plan of action should a player pursue always bearing in mind the potential actions of the adversary or the opponent. In a loose manner, recreational games of dispute fall easily into that set of games that economic game theory tries to explain, but more important than that is game theory's concentration on interaction through dynamic rationality. The player adopts an optimizing strategy not according to an abstract collection of logical principles, but in a dynamic relation to another interactor (whether a human being or a digital program). This is what Robert J. Aumann (2000) calls individual rationality.

If that is true, how to explain games that players play alone? What are the players doing in this case? Is a solitary game an anti-social experience, or is there another trait besides interaction that may define the gaming experience? To produce a transmedial definition of games, Juul (2003) contends that, despite their multiple features, games (all kinds of games) share similar properties. In games, players must be aware that their behavior is, like all social behavior, demarcated by rules, although not determined by them, for deviance and cheating are persistently feasible. Such rules are integrated in an autonomous, systematic and formal manner, as is the case - for example - "Extreme Boards and Blades," "Muscle Car 3," "Rebel Trucker," and "Grand Theft Auto 3."

Yet, even before rules of interaction of both end-users and in-game scenarios are established, game design must lay down the physics of the virtual world. Game design determines the technological and digital tools that are the foundation and the unity active in any of the game's interactions. The foundations are the laws, the physics at work all over the virtual universe of the game. If these laws are developed consistently and correctly, the player will be immersed in a total world that may or may not follow the physical strictures of nature. The player can then collide, fly, and jump with or without gravity's limits. In all kinds of settings, whether in fantastic or realistic universes, laws are the basis for the game virtual experience. The choice of the set of game laws must be made in complete agreement with the experience presented to the player. If this criterion is not met, the development team of the game will certainly fail: To give life to a game design, the developers must be in the technological forefront of programming innovation, searching for the most advanced systems of simulated physics, artificial intelligence, and graphical rendering systems. Programming errors, popularly known as bugs, disrupt the 
player's suspension of disbelief, forcing the players to guide their attention on the design flaws of the virtual system, instead of the unfolding experience of gameplay.

The degree of success or failure of game developers and designers is directly proportional to the players' immersion in a virtual world. The player must be allowed to uncover game elements in a natural state of discovery and experience as in reality - therefore providing the player a game design that is not dictated, but instead actively interactive. Baggaley (2002: 282) establishes the basic condition for the immersion of players: "To ensure that the player remains immersed in the experience, the game designer must keep as much of the needed exposition as possible within the interactive game world." The players must thus accept the totality of the virtual universe that is offered to them. Without that, the players' immersion is unattainable, and so only after the determination of the laws of the game can the rules of interaction begin to be digitally implemented.

It is correct to state that the rules of video games function as laws, but it would be more precise to identify rules as procedural of gameplay, and yet not worldly to the game environment or virtual world. Procedural rules are therefore elements of game design and can be used to define modes and sets of rules of gameplay. The institution of rules determines the player's satisfaction with gameplay. By nature, rules are arbitrary: A set of rules may be too restrictive or void of restrictions, depending on the game's objectives. As result of their essentially arbitrary nature, rules can even enable a temporary relief from the laws of the digital game. In the same spirit, a set of rules, in fact a mode may require the player to finish the proposed, required, or suggested task before a certain time limit expires. Moreover, sections, levels, or features of the game may not be unlocked until the task is accomplished under the conditions demanded by an array of rules. Rules indicate the availability of competitive factors, under the form of non-player characters, and by that it is meant incidents such as hindrances, obstacles, weapons, vehicles, as well as goals and rewards. Rules are actively constitutive of games, and for that reason, they must be put in place prior to the interaction of players.

Now talking of all kinds of games, digital ones included, gameplay is more than the search for outcomes. Games have outcomes that result from conditions, from rules that are mutual and reciprocal. The mutuality and the reciprocity of rules grant legitimacy to disputes between players. Rules are shared components of playing; they should also be common knowledge to all players in a game. Rule sets may be displayed on the load screen (the screen that is used as wallpaper while game assets are being rendered and processed for gameplay), and therefore adhered to any player that continues from the point of interaction. Because of the constitutive nature of rules, players behave uniformly in the way they do. The reciprocal acceptance of rules explains why players of some online games play, in groups, strictly against computer generated opposition, while other online games are played with players opposing each other. How many games can one play with the same deck of cards? There will be as many card games as there are constitutive rules accepted and known by players. Rules are present all throughout games. Rules confer unity and identity to a game. A rearrangement of rules indicates a new game, or in video games - a new mode of gameplay. Rules are not supposed to be questioned, or disputed, or changed as the gaming progresses: They must be followed even in the paradoxical situation when the rule is freedom from rules.

Despite their constitutive role establishing levels of secure interaction among players (as well as fairness in disputes), one should not assume that rules are capa- 
ble of describing and prescribing the outcome of a competition. That would imply the automatic disregard of the creative actions and strategic choices of individual players. Rules are akin to a score in a concert. Rules and scores guide possible actions, but performance is far more than following rules and scores.

If one grants to rules the status of the prescribed essence of a game, the inference would be - like Claude Lévi-Strauss (1962: 48) states in La Pensée Sauvage - that playing a game is no different from being involved in a ritual. Games and rituals may have some family resemblance: They are social practices actualized through rules, but, considering that the performance and the actions of players in a game produce winners and losers, norms and prescriptions do not establish the outcome of playing a game. Moreover, conforming to rules - even in the case of rituals assures that outcome is legitimate. Rules are consistently present in dispute because of their effect over an outcome. Performing a ritual, following conventions and shared rules, can also be a way of distinguishing individuals. Take into account video games with modes designed for training exclusively. Game rules are conceived as an exercise for the benefit of the player alone who wants to evolve past the initial learning curve, and start the game with improved strategic means. This is an example of a situation in which the player faces his/her own inadequacies with the goal of achieving better performance. As always is the case, in any game, whether digital or not, and in rituals, performance harvests prestige and reputation for an individual. Complying with a group of accepted rules not only avoids for the players the tag of being of low worth, but also ensures that the outcome is unquestionable.

That is not different from the case of rules stored as a system of algorithmic clues in a computer game. Even more so than in human social interaction, in video games a series of procedural rules is robustly realized, offering courses of the game play, and fully driving - although not shaping completely - the player's movements. The player cannot freely change or bend the embedded norms of procedure. Whoever plays in a computer must follow the given clues to constitute the experience of game playing. In games of extreme sport, the course of actions can be free, but the assessment of someone playing a digital skate board game - for example observes the parameters established in the computer program. What the program does is to serve as a means of assessing the performance of the player. Then, two plans of action are pitched against each other. The player must act freely from the strictures of the program, generating a strategy outside of the design, whose tree of potential solutions has been algorithmically laid down. That is why players engage in a digital game setting: They do it to achieve personally desired - and yet variable - outcomes.

The simplified design grid of the digital game Rebel Trucker (Table 1) illustrates how a player's initial choice prompts a set of choices. The paths are designed and developed for entertainment, but the player is the one who decides what is entertaining. The player has the binary and excluding option of defining their player status, meaning that "[i]n every game, players are continually being presented with costs and tradeoffs. A cost doesn't have to mean money or victory points; it can be simply the things you had to succeed at before you could get to the options you're facing next. What is the real cost of a game choice - in terms of time, effort, attention and alternative resources to get there?" (Rollings \& Morris, p.77) The choice made will determine gameplay attributes, which lead to in-game scenarios that alter the playing experience. Also, these choices lead to paths of gameplay that may 
or may not satisfy the player's objective, but regardless of satisfaction, information about cost and benefit, risk and achievement are gained. Now, the player is redefined in a way that the game designer and the game state should match.

Table 1. Rebel Trucker - Tough truck driver or Sissy stool pigeon?

\begin{tabular}{lllll}
\hline $\begin{array}{c}\text { Modes } \\
\text { (choice) }\end{array}$ & \multicolumn{1}{c}{$\begin{array}{c}\text { Cargo } \\
\text { (arcade) }\end{array}$} & \multicolumn{1}{c}{$\begin{array}{c}\text { Long haul } \\
\text { (simulation) }\end{array}$} & $\begin{array}{r}\text { Career } \\
\text { (storyline) }\end{array}$ & $\begin{array}{c}\text { Player Rebellion } \\
\text { (disregard design) }\end{array}$ \\
\hline Path & Short missions & Certification & Work for mob & Free to explore \\
Path & Time limits & $\begin{array}{l}\text { Delivery/pickup } \\
\text { load }\end{array}$ & Work for FBI & Free to interact \\
Path & Points gain/loss & $\begin{array}{l}\text { Obey Trucking } \\
\text { laws }\end{array}$ & Refuse both & Free to evolve \\
\hline
\end{tabular}

Although the player faces a pre-determined set of unambiguous and definite algorithmic alternatives, to a point that a digital game is beyond the influence of the player, it is fair to declare that, through the player's choices and performances, "the game changes the player that plays it" (Juul 2005: 96).

Players may predominantly wish to win a game, but it is quite feasible to imagine exceptions, as in the case of a father, who wants to encourage a son or a daughter to improve his or her playing skills, making every move to lose the game. Again, the game provides experience and information, and the parent should recognize the child's status and progression - therefore changing the parent's strategy accordingly. More than searching blindly and mechanically for a rigid victory, players must have a definite point and an outcome in mind when involved in a game; and - but not always - frequently point and outcome overlap.

It is thus also quite reasonable to expect that players will devote themselves to produce the intended outcomes. Because the players desire an outcome, Juul (2003) presumes his/her attachment to a previously designated goal. However, if the desired outcome is not a given, but a variable result, embodied in the formal system of the game, the outcome is a challenge. The player then feels that the effort expended during the gaming process is justified, although depending on the situation and context of each particular game challenge, the player may or may not be quite enthusiastic about the necessary effort to be successful in the fame. Variable outcomes presume more than victory and defeat; they indicate a progressive scale of payoffs.

\section{Games and Players}

In several game settings - such as parlor games and sports - the main trait of playing is conflict of interest. That was von Neumann and Morgenstern's hypothesis when they compared economic competition to poker. Economic competition and poker playing would always end in a winner takes all situation. In the same way that the interests of competing economic agents collide, the poker player who has the higher hand of cards will consequently collect his and her chips as well the ones of the players with lesser hands. Each chip taken by the winner is a chip that his/her opponent lost. In mathematical terms, the addition of plus one with a minus one is always zero: $(+1)+(-1)=0$. Technically, poker playing is a zero-sum game.

As games of extreme competition, zero-sum games are unashamedly committed to selfishness. In zero-sum games players try to implement - with different success - strategies that will simultaneously maximize their gains, while minimizing their losses. The interactive gamers in zero-sum competitions bluff (which is authorized 
deviance) or even cheat. The optimal strategy in zero-sum games is always a minimax plan of action: minimizing losses, while maximizing gains. The outcome of the game is the one in which $A$ wins, while $B$ loses, or vice-versa: $A$ loses while $B$ wins.

Nonetheless, when a buyer and a seller close the deal of a car, for instance, that does not mean necessarily that one player lost, while the other won. Both economic agents can win: The buyer gets the car that he/she wants, and the dealer sold the car with a margin of profit. Buyer and seller reached an equilibrium point, from which ideally none of the players have any reason to depart. This is a non-zero sum game. In non-zero sum games, interests do not collide; they meet a common point.

However, if a player interacts with a digital game, one cannot say that he/she is colliding with the computer or meeting a common point. The interaction with the game's system of algorithmic clues is of a different type. Outcomes such as win/lose and lose/win of zero-sum games, or win/win and lose/lose of non-zero sum games are either irrelevant, or not even a possibility. In video games, outcomes do not define playing. Something more general than an outcome is needed.

As previously suggested, the point, and not the genre, is what define video games. The point of video games is to face a formidable opponent, the omniscient programmed computer laid into the machine prior to any playing. The thrill of playing comes from the impression that he/she is overcoming a supreme adversary. The player and the computer have no conflict of interest; frequently end-users do not play against other end-users.

Digital programs merely follow the players' actions. Therefore, video games are inevitably one-player games. The de facto opponent cannot be the set of previously conceived algorithmic choices. How can the computer be a leveled adversary of the player if its digital program is in charge of all alternatives? The actual opponent of the player has to be paradoxically no one but the player himself/herself, whose recurrent actions measure his/her present abilities. No greater degree of selfishness is possible: the players are involved in the radically self-centered experience of a zero-sum game in which they are the sole player. Is it surprising that self-absorption is the governing feature of video games?

However, the suggestion that the player has gains is consistently embedded in the design structure of a great number of video games, either under the form of overcoming hurdles or living out a scenario. Yet the player cannot gain a victory in the strict sense of the word because he/she is not facing an adversary. Superficially, the player appears to have accumulated points, but that cannot be the dominant point of playing. What is attractive to the end-user is the opportunity of adding skills and capacities to a previous and evolving repertoire or inventory of abilities. For that reason, game playing must offer to players the chance of becoming better and better in the game that they chose to perform. Again, the game cannot be about the actions and the events around the in-characters and the scenarios that structure gaming experiences. The game is all about the players themselves, and that is the fundamental reply to the puzzle of deep immersion as well as the effect of full absorption on the part of end-users.

\section{Virtuality and Virtuosity}

Digital game development follows a blueprint -frequently named The Design Document- in which gameplay details, technical specifications, and developmental architecture are laid out. The idea is that, in this document, each aspect of the game is 
fully described, but with consideration for technical deviations. From the viewpoint of product design, the developmental logic of video games is an initial progression from the whole to the parts, while complemented by the evaluation of how and if the parts adequately fit, thus leading to potential alterations in the way the design had been at first conceived. Yet, from the viewpoint of the end-users' experience, the players have partial and progressive access to the totality of the game, even if the totality is established a priori, albeit provisionally, since the earliest stages of the design. The virtuality of the game design and the virtuosity of end-users are the two complementary features and attributes of video games.

The Design Document is more than a mere technological tool; it actively defines how an imaginary end-user can achieve improvement through strategic choices made during gameplay. Whatever the game is, whether occurring in a fantastic setting, or simulating a real life situation, in any case always unfolding in virtual environments, in virtual worlds, gameplay is established so that the player achieves virtuosity. Virtuosity broadens the player's experience and capacity for more challenging gameplay. This is an effect where the player evolves as a result of playing the game, an effect that can have an impact on the player's real world experience, as in the case of military pilots able to get a plane off the ground and return it with a safe landing, never actually flying a plane before, only because a flight simulation had provided them the experience - risk free.

The role of the Design Document determines the developmental milestones of the game in all of its aspects, ranging from requirements of game completion to the final characteristics that will be offered to the public. Video games are ever changing organic entities that are developed not simply as the software is designed, but also as marketing strategies. It is perhaps trite to emphasize it, but video games survive or perish in competitive markets, where the products are successful in direct relation to their innovative features and player satisfaction.

If the immersion of the player in gameplay attributes is the factor that brings in sales, the discovery and the improvement of new means of immersion is a constant goal in game design. Because the games must sell, and the players buy products that have innovation, video games and players are involved in a process of co-evolution. Why buy a new game that simply repeats what other games have done before? Why go through the same experience if the result is wholly predictable? Redundancy is not only incompatible with immersion: it is the technological opposite of innovation.

Consider the phenomenon of sequels. A successful game is offered again to the market, but it must present definite innovations. While it is quite true that market demands allow the game designer to provide sequels of the original game design, this possibility comes with conditions. The players expect more gameplay from sequels as they have evolved as players, and require more semiotic stimuli and innovative features. This progression feeds the need for new modes of play that advance both the state of game design as well as player interaction. For this reason, one cannot say that the end-users face a completely adversarial computer program. Emerging gameplay indicates to players the possibility of improving their previous physical, mental, and emotional responses. The game design is an enabler, although presenting escalating obstacles and difficulties.

As the gameplay progresses, and as the player moves to higher and higher levels of achievement, the outcome should point to an improvement of the end-users' initial mental, emotional, and physical responses, generating the gratifying sense 
of having done what was not possible before. That is the function and purpose of modes of playing. Through the set of rules that compose each mode of playing, the end-user is steered into scenarios of action, objectives, and rewards. The sequence of modes of playing is a definite progression, affecting the player as a whole. In this sense, and as such, video games are a new media, radically different from traditional media. In traditional media, the spectator is no more than a passive participant, frequently a mere voyeur. New interactive media is wholly active with direct effects over the player who is allowed to experience the exciting transformation of his/hers initial abilities.

In a game like Muscle Car 3, for instance, the player has the chance to train in one mode of gameplay, called 'Testdrive', in which it is possible to drive on tracks without opponents and time restrictions. The experience in this mode of gameplay is the one that prevails in arcade games. The end-user has a view of what he/she can do in a world without competition or challenge. However, when the player chooses the mode called, 'Checkpoint', the player must race against six other drivers, and complete the race in the top three places to open new racetracks. Another mode, 'Career', allows the player to ride around a city free of time restrictions. The player may challenge vehicles to street races, and should avoid the police This mode of gameplay puts the end-user in direct relationship to what can be a closer simulation to real-world and underground racing experiences. The initial arcade experience is left behind and the ante has increased.

\section{Playing Digital Chicken}

Although without the risk inherent to real-life situations, video games are strikingly similar to a game called Chicken. In real-life, Chicken is a zero-sum game of intense risk that reveals the intrinsic personal qualities of the players. The most famous game of Chicken is shown in an American movie of the 50s, Rebel Without a Cause, despite the fact that the standard description of Chicken is quite different from the movie scenario. In Rebel Without a Cause, the game is referred to as "chickie, run": cars do not collide, but they are driven toward a cliff.

In the canonical game of Chicken, two drivers speed up cars going toward each other. The collision seems inevitable: if one driver does not swerve, the crash may be fatal. In real-life, Chicken is a two-person zero-sum game with potentially awful consequences, as the script of Rebel Without a Cause dramatizes the outcome of playing reckless "chickie, run".

The end of games of Chicken is reached when at least one of the drivers (although sometimes both) swerves, avoiding the crash; but the one who dodges the crash loses, and the loser is publicly humiliated, symbolically and socially "slaughtered", and dubbed "chicken". Video games are Chicken games played in an environment of multiple scenarios that may include human against human, human against machine, and all the variables between. Digital gaming. though simulated and controlled, is a virtual world that requires strategy and challenges just as Chicken does. The goal of real-life Chicken and digital chicken games is to reveal the personal qualities and attributes of the ones who are challenged. And yet, video games are games of Chicken with one significant difference and social advantage: if the opponent defeats the end-user, he/she can try it again, without public shame or death. In the end, after subsequent attempts the player will eventually became better and better. Digital Chicken is brinksmanship without a physical personal price, a mode of play that is not lethal or fatal. What seemed impossible to occur happened to the 
game of Chicken: it is feasible to play Chicken digitally with tolerable humiliation, without symbolic and social death, and moreover without risking one's physical integrity. Digital Chicken is a tamed game, which makes the real and dangerous game of Chicken far more exciting. Video games transformed Chicken into a useful, attractive, and yet harmless parlor game.

Like Chicken, video games also build reputation: they assess personal qualities and attributes, revealing the end-users' virtuosity, under multiple forms: in a horror game, the lights blink out and it is evident the inmates are free to roam the asylum. This sign can put the player on edge. Then some bizarre creature, never seen before, jumps out of the dark at the character in the game; the player has an emotional response of moving in the seat and maybe even freezes and loses a life the first time. Undoubtedly, the monster is only on the screen, but the player's flinch mechanism kicked in all the same. This and other end-user's reactions to the event's in-game can only be defined as the result of immersive gameplay; the ability to have control in similar situations is the result of virtuosity.

That is not all: Outside of the game, the player has been changed too. The player has gained personal information about himself/herself, which in turn, has improved his/her neural processing of similar data. A player using game input has acquired information that included reactionary functions of output, hand and eye coordination, as well as the capacity of performing physical actions, even when the game is over.

In both video games and in real-life Chicken, the behavior during gameplay must be asymmetrical. The end-user must not follow the same strategic plan of the opponent, whether a human end-user or a computer. That is the case, because all games of the mode Chicken have two structurally excluding equilibrium points that solve the game. The solution is not strategic, but wholly dependent upon the personal qualities of the players. The equilibrium points are: 1) end-user outdoes the computer (in real-life Chicken, driver $A$ does not swerve, but the opponent $B$ avoids the crash, losing the game); 2) the computer outdoes the end-user (in real-life Chicken, driver A swerves and loses, while $B$ stays the course and wins the game).

As is always the case with games of Chicken, in video games, the end-user (or end-users against one another) and the computer must follow different and asymmetrical strategic plans. The plans of action do not define the outcome of the game: in real-life, if both players stick to the same plan of action, the result is either a tie (both swerve), or a catastrophe (both stay the course and collide). In either case, bearing in mind that zero-sum games demand a win or a loss, the game ends without a solution. In real Chicken and in video games, the two players (the end-user and the computer, or in the case of humans playing against one another) should follow opposite plans. Real-life Chicken is a game whose outcome is either power or dishonor (the winner calls the loser "chicken"); but - as said before - without paying the potential price of symbolic, social, or actual death, the end-users demonstrate their hierarchical qualities, displaying clout and virtuosity.

In real-life, the solution of games of Chicken does not come just from the implementation of an optimal strategy. Victory depends on dissuading the opponent of driving head on. The optimal strategy of driving straight toward collision is a prerequisite for victory; but what defines victory is the capacity to drive straight, and at the same time to force the opponent not to pursue the optimal strategy, not just out of fear, but mainly as the result of the certainty that the player will not give in at the last moment. 
The vivid and intense sense of liveliness in real and video games comes from the experience that the game is decided at the brink of the last moment. Indeed every stage of the game is a last moment. Nothing can be more akin to life itself, for life is succession of last moments, and moments are a succession of last seconds. No excitement and feeling of deep immersion can be greater than this one. In this type of demand, immersion has to be total, for the decision of the game can be reached at the flickering fiat from which life hangs on. Of all games, only Chicken can express the fullness of this ordeal. Games must go on until the smallest fraction of time before the final crash. Up to the last moment, the player can turn the game on his/her favor; and they ought to try to do that: the payoff is survival or extinction, defeat or victory.

The success of playing Chicken depends on intimidating the opponent to give up on the optimal strategy. The solution of Chicken is not in the driving, but in the signs that are sent to the opponent. The winner delivers signs whose role is to force the other player to do it differently. The winner is not a strategist only, but the player who can personally do what the opponent cannot do.

\section{Interactive and Digital Semiosis}

We must now develop, in terms of games, the insight coming from the notion that that the solution of the real-life Chicken emerges from the signs sent from one player to another. In real-life Chicken, the solution comes when the player persuades the opponent that he/she will truthfully drive head on. To convey his/her intent, the player has to send more than the signs that he/she deems as truthful. The delivered signs must be representations forceful enough to influence the opponent before the crash; otherwise the game is not won, and ends in collision. Collision is more than a tie: it puts the player at severe risk.

In games, the expression "the sign is on the wall" is more than a literal statement. Signs are on almost everything. In reality, a billboard on the interstate may merely advertise a product, however in a game it has another purpose. The same sign, represented in a driving game, may present a cue to the player or it may be there to further immerse him/her in a virtual world. The sign, instead of advertising a film called Earthquake, is a clue that the suspension bridge will be demolished. If the sign is not interpreted appropriately, the player cannot escape danger, and therefore loses a life in the game.

Signs, cues, and symbols work together in the game and are created to immerse the player in a world that must be constantly reinterpreted as the hinting signs of something else. The hints are not always fully conspicuous. The player experiences the semiotic texture of the game, indeed the structural elements of game design, and then learns to react to this data in an more efficient way. Conversely, perception and game experience increase the player's involvement and his/her ability to achieve greater player's status. This is a factor no game designer can afford to ignore. "On occasion, a well placed symbol can generate cognitive resonance in the player." (Lamaree, P.269) During their first appearance, gameplay hints (cues, signs, and symbols) bring about mental, emotional, or physical responses, not necessarily conscious, but always immediate. The player knows that all attention is demanded, and that is an immersion factor of gameplay. At the second time, the player will have a more controlled response and may even achieve something formerly not possible. At this point, when a player sees, for the second time, a sign saying Earthquake, he may already have his finger sitting on the B-button ready 
for the broken bridge that is around the corner. The player has used the experience to become ready and more capable.

The delivery of signs follows the classical principle of semiosis. The actual material sign must be considered in relation to what the receiver can interpret. The interpretation of sign, a posterior semiotic action, should embody the intent and express the true resolve of the sender. The sent sign address a receiver, creating in the receiving mind an equivalent of more developed representation.

\section{Game Over}

This paper recognizes that games are composed of multiple layers. Besides details and procedures concerning the market possibilities of the game as an economic product, the game design can establish a narrative level in the case of fictional games, but that is not even a strict necessity. An interesting digital game should allow the player to have the freedom to skip a narrative plot. That is commercially attractive for it expands the market of potential buyers, thus including gamers who can simply not be interested in the narrative, but attracted to the technological advances of this particular gameplay. Thus, coming from the study of traditional media, theories of literary narrative do not deal fully with the experience of video games. Furthermore, games of sport, simulation, and training are also part of the digital game world, although devoid of narrative.

Despite the fact that it is a component of the gaming experience, virtuality does not define gameplay. Virtuality is the net of possibilities for the virtual environment and the end-user: it is the lattice upon which the player performs. Virtuality lays out a world of possibilities, while playing is decisively and to varying degrees sheer virtuosity. Virtuosity is not what is merely possible; virtuosity is the actual. Virtuality exists so that virtuosity may be exercised or demonstrated. Virtuality triggers immersion. Immersion is feasible because the players perform at his/her level of virtuosity, attempting to improve previous performance. Virtuosity is always performance. $^{6}$

The relation between virtuality and virtuosity is akin to the one that holds an energy field together. Virtuality is a weak force, while virtuosity is the strong force of video games: virtuality emerges from the pressures of deep immersion in gaming experiences. Virtuosity demands nothing less than the whole constitution of the players, who must engage physically, emotionally, and mentally in the experience that virtuality proposes; and that is what responds for the profound effect of games on gamers. Moreover, that is why graphic art of video games may appear to be ugly, clumsy, rough, and awkward for a non gamer, and yet rather effective for players. The illusionary effect of video games has nothing to do with mimetic trompe-l'oeil. The player is not immersed in the visual art and the look of a game.

The experience of video games redefines the nature of illusion as much more than absorption of an image into the object that it intends to represent. Digital illusion is a short script for immersion and deep thought. The player and the totality of

\footnotetext{
${ }^{6}$ Although this phenomenon does not occur presently in the United States, in South Korea, extraordinary players of the game are pros. Ten of thousands of spectators flock to stadiums to see players like Derek Jeters and Peyton Mannings, top performers of an online game, StarCraft (Schiesel 2006). Video games are featured in Korean sports channels. South Korea has almost twice the number of broadband subscribers per 100 inhabitants than the United States, which contributes to the generalized fever for online video games. However, in both models of consumption of video games, the solitary one in America and the South Korean two-person-zero-sum gaming, the dominant characteristic of video games is individual excellence in performance.
} 
his/her experience is at the core of gameplay; as he/she is involved with all of his/her capacities and abilities. This is the threshold of immersion: "immersion is mentally absorbing and a process, a change, a passage from one state to another" (Grau 2003: 13).

So, among all games Chicken is the one that accounts for total mental immersion, brinksmanship, escalation, revelation, and expression of the individual power of players. As we demonstrated, the underlying presence of Chicken in video games explains the intense and vital experience that not only fascinates so many players, but also constitutes the dominant trend of what has been appropriately called the new media.

\section{Games}

Rockstar Games. Grand Theft Auto III. Take-Two Interactive, PS2, 2001.

Silverfish Studios LLC. Extreme Boards and Blades. Activision, PC, 1999

3Romans LLC. Muscle Car 3. Global Star Software, Take-Two Interactive, PC, 2003

3Romans LLC. Rebel Trucker: Cajun Blood Money. Global Star Software, Take Two Interactive, PC, 2004

\section{References}

Aumann, Robert J. (2000). Collected Papers. Cambridge, MA: The MIT Press.

Baggaley, Sean T (2002). Show and Tell: Applying Screenwriting Techniques to Computer Games. In Game Design Perspectives. François D. Lamarée, 281, 282 Hingman, MA: Charles River Media, Inc.

Bogost, Ian (2006). Unit Operations: An Approach to Videogames Criticism. Cambridge, MA: The MIT Press.

Grau, Oliver. Virtual Art: From Illusion to Immersion.; translated by Gloria Custance, Cambridge, MA: The MIT University Press.

Holin, L., \& Sun, C. (2003). Problems in simulating social reality: Observations on a MUD construction. Simulation \& Gaming 34, 69-88.

Huizinga, Johan (1994). Homo Ludens. Boston: Beacon Press.

Jana, Renee (2006). Enough with the shoot-'em-ups. Business Week, October 16, 92.

Juul, Jasper (2003). The game, the player, the world: Looking for a heart of gameness. In Level Up: Video games Research Conference Proceedings, Marinka Copier and Joost Raessens, 30-45. Utrecht: Utrecht University.

Juul, Jesper (2005). Half-Real: Video Games Between Rules and Fictional Worlds. Cambridge, MA: The MIT Press.

Lamarée François D, ed. (2002). In Game Design Perspectives. 269 Hingman, MA: Charles River Media, Inc.

Maynard, Smith, John (1982). Evolution and the Theory of Games. Oxford: Oxford University Press.

Nash, Jr, John F. Reprint. The bargaining problem. In Classics in Game Tneoyr; Harold W. Kuhn (ed), 5-13. Princeton: Princeton University press. Paper originally published in Econometrica 8 (1950), 155-162.

Rollings, Andrew and Morris, Dave (2004). Game Architecture and Design: A New Edition. Berkeley, CA: New Riders Publishing.

Schiesel, Seth (2006). The land of the video geek. The New York Times, October 16 , online edition. 
Sebeok, Thomas A, (1981). Naming in animals, with reference to playing. Semiotic Inquiry 1, 121-135.

Turkle, Sherry (1984). The Second Self: Computers and the Human Spririt. New York: Simon and Schuster.

Turkle, Sherry (1996). Constructions and Reconstructions of the Self in Virtual Realities. In Eletronic Culture, edited by Timothy Druckery, 354-365. New York: Apparatus.

von Neumann, John and Morgenstern, Oskar (1944). Theory of Games and Economic Behavior. Princeton: Princeton Univrsity Press. 